\title{
Iogurte produzido com cajuí (Anacardium othonianum Rizz)
}

\section{Yogurt produced with cajuí (Anacardium othonianum Rizz)}

\author{
Camila Martins Fonseca ${ }^{1}$; Cleube Andrade Boari ${ }^{2 *}$ \\ Pedro Henrique Ferreira Domingues ${ }^{3}$; Dênia Patrícia Meira ${ }^{1}$; \\ Luisa Silvestre Freitas Fernandes ${ }^{1}$; Mariana Almeida Dumont ${ }^{4}$
}

\section{Resumo}

Caracterizou-se iogurte adicionado com polpa de cajuí em concentrações de 5\%;10\%;15\%;20\% (m/g). Determinações de acidez, $\mathrm{pH}$, proteína, massa seca, firmeza, consistência, coesividade e quantificação de bactérias láticas foram conduzidas nos tempos $0,10,20$ e 30 dias. Identificação de compostos voláteis e testes sensoriais de preferência, aceitação e intenção de consumo foram realizados no primeiro dia de vida útil. Foi preferida a formulação com menor proporção de polpa $(5 \%)$, a qual coincide com menor acidez. Não houve efeito significativo $(\mathrm{P}>0,05)$ da quantidade de polpa adicionada e do tempo de armazenamento sobre massa seca, contagem de bactérias láticas, firmeza, consistência e coesividade. Acidez e $\mathrm{pH}$ foram significativamente influenciados $(\mathrm{P}<0,05)$ tanto pela quantidade de polpa adicionada quanto pelo tempo de armazenamento. Teores de proteínas foram significativamente menores $(\mathrm{P}<0,05)$ quanto maiores as quantidades de polpa adicionada. Além de compostos de aroma de ocorrência natural no iogurte foram identificados voláteis de ocorrência em Anacardium (butanoato de etila, butanoato de metila, etanol, hexanal, benzaldeído e 3-metil butanoato de metila). Há potencial tecnológico na produção de iogurtes com cajuí com adição de polpa em proporção de 5\% ao volume total de iogurte produzido.

Palavras-chave: Frutas, cerrado, leite fermentado

\begin{abstract}
Yogurt added with $0 \%, 5 \%, 10 \%, 15 \%$ and $20 \%$ of cajuí pulp (Anacardium othonianum Rizz) were characterized. Acidity, $\mathrm{pH}$, protein, dry matter, firmness, consistency, cohesiveness and quantification of lactic acid bacteria were conducted at $0,10,20$ and 30 days. Identification of volatiles compounds and sensory tests of preference, acceptance and consumption intention were performed on the first day of shelf-life. Preferred formulations are those that contain smaller proportions of pulp (5\%) which coincide with lower acidity. There was no significant effect $(\mathrm{P}>0.05)$ of the amount of pulp added and storage time on dry matter, lactic acid bacteria count, firmness, consistency and cohesiveness. Acidity and $\mathrm{pH}$ were significantly influenced $(\mathrm{P}<0.05)$ by the amount of pulp added and storage time. Protein levels were significantly lower $(\mathrm{P}<0.05)$ with the increase in the quantity of pulp added. Volatiles compounds in cajuí yogurt include ethyl butanoate, methyl butanoate, ethanol, hexanal, benzaldehyde and 3-methyl butanoate. There are technological potential in the production of yoghurt with cajuí with addition of 5\% in proportion to the total volume of yogurt produced.
\end{abstract}

Key words: Fruit, brazilian savana, fermented milk

1 Discentes de Mestrado em Zootecnia, Universidade Federal dos Vales do Jequitinhonha e Mucuri, UFVJM, Diamantina, MG. E-mail:kmilazootecnista@gmail.com; denia.meira@yahoo.com.br; luisasilfer@yahoo.com.br

2 Prof., UFVJM, Diamantina, MG. E-mail: c.boari@ufvjm.edu.br

3 Discente de Graduação em Zootecnia, UFVJM, Diamantina, MG. E-mail: pedroufvjm@yahoo.com.br

4 Zootecnista, Técnica de Laboratório, UFVJM, Diamantina, MG. E-mail: mariana.dumont@ufvjm.edu.br Autor para correspondência 
Em decorrência de sutileza de textura, aroma e sabor o iogurte pode ser considerado como um excelente veículo para ingredientes não lácteos, como polpas de frutas. A incorporação de frutas ao iogurte, além de agregar nutrientes, também propicia inovação sensorial e diversidade de cor, aroma, sabor e textura, atributos pelos quais os consumidores mostram-se cada vez mais ávidos.

Dentre as frutas do Cerrado brasileiro, o cajuí (Anacardium othonianum Rizz), em função de seu sabor e aroma peculiares, apresenta potencial para utilização na fabricação de iogurtes. A polpa do cajuí (Anacardiaceae) apresenta coloração amarelada e se constituí, em média, por $1,18 \mathrm{~g} .100 \mathrm{~g}^{-1}$ de proteína, $0,63 \mathrm{~g} \cdot 100 \mathrm{~g}^{-1}$ de extrato etéreo, $6,97 \mathrm{~g} \cdot 100 \mathrm{~g}^{-1} \mathrm{de}$ carboidratos, perfazendo energia metabolizável total de $38,27 \mathrm{Kcal}_{1} 100 \mathrm{~g}^{-1}$ (SILVA et al., 2008).

Embora bastante apreciado e com grande potencial para o processamento agroindustrial, o cajuí ainda é subexplorado. Sua principal utilização consiste na produção de polpas congeladas, as quais conhecidas e comercializadas em âmbito regional. Seu emprego para a elaboração de iogurtes, além dos benefícios nutricionais e da inovação sensorial, pode ser uma alternativa viável à valorização desta fruta, o que poderia contribuir, também, ao desenvolvimento sustentável do Cerrado, promovendo riquezas e ocupação.

Considerando-se o exposto esta pesquisa foi conduzida com o objetivo de caracterizar iogurte produzido com adição de polpa cajuí.

Quantidades suficientes de leite bovino in natura foram processadas após realização de análises de controle de qualidade (BRASIL, 2002). Lactose $\left(4,59 \pm 0,25 \mathrm{~g} \cdot 100 \mathrm{~g}^{-1}\right)$, proteína $\left(3,8 \pm 0,21 \mathrm{~g} \cdot 100 \mathrm{~g}^{-1}\right), \quad$ gordura $\quad\left(4 \pm 0,41 \mathrm{~g} \cdot 100 \mathrm{~g}^{-1}\right)$, sólidos desengordurados $\left(8,3 \pm 0,18 \mathrm{~g} \cdot 100 \mathrm{~g}^{-1}\right)$, densidade $\left(1,03 \pm 0,004 \mathrm{~g} . \mathrm{L}^{-1}\right)$ e índice crioscópico $\left(-0,55 \pm 0,032^{\circ} \mathrm{C}\right)$ foram determinados empregandose o analisador ultrassônico Milkotester ${ }^{\circledR}$ (Modelo LM2, Série 10296). A determinação da acidez titulável $\left(16,9 \pm 0,32^{\circ} \mathrm{D}\right)$ foi conduzida em atenção à metodologia proposta pelo Instituto Adolfo Lutz (INSTITUTO ADOLFO LUTZ, 2008).

Cajuís, de mesma safra e em estádio de maturação semelhante, foram colhidos no município de Chapada Gaúcha, Minas Gerais. Pedúnculos do cajuí foram selecionados de acordo com sua integridade, limpos em água corrente (10mg.. $\mathrm{L}^{-1}$ de cloro residual livre), sanitizados em solução de hipoclorito de sódio (200mg. $\mathrm{L}^{-1}$ de cloro residual livre) por 30 minutos, drenados e resfriados à $4{ }^{\circ} \mathrm{C}$. Posteriormente, foram processados em processador industrial com $10 \%(\mathrm{~m} / \mathrm{v})$ de água potável a $4{ }^{\circ} \mathrm{C}$, por 8 a 10 minutos, sendo o homogeneizado peneirado, envasado em sacos de polietileno, congelado em congelador doméstico $\left(-12^{\circ} \mathrm{C}\right)$ e assim mantido até o momento de produção dos iogurtes (15 dias). $\mathrm{Na}$ data de fabricação dos iogurtes a polpa foi descongelada sob refrigeração $\left(4^{\circ} \mathrm{C}\right)$, pasteurizada a $65^{\circ} \mathrm{C}$ por 30 minutos e resfriada $\left(4^{\circ} \mathrm{C}\right)$. A polpa foi avaliada quanto a acidez e $\mathrm{pH}$ (INSTITUTO ADOLFO LUTZ, 2008).

Foram desenvolvidos iogurtes com adição de polpas em quatro concentrações: $5 \% ; 10 \% ; 15 \%$; $20 \%(\mathrm{~m} / \mathrm{g})$. A adição de sacarose (açúcar cristal) foi padronizada para $10 \%(\mathrm{~m} / \mathrm{g})$ no produto final, considerando-se a adição de polpa. O controle consistiu em iogurte obtido pela fermentação do leite com adição de sacarose $(10 \% \mathrm{~m} / \mathrm{g})$.

Para a fabricação do iogurte procedeu-se a dissolução e homogeneização do açúcar cristal no leite cru resfriado $\left(4^{\circ} \mathrm{C}\right)$, sendo a mistura filtrada em coador de nylon, para a remoção de sujidades possivelmente presentes no açúcar, e submetida à pasteurização $\left(65^{\circ} \mathrm{C}\right.$ por 30 minutos $)$. Após pasteurização, a mistura foi resfriada para $45^{\circ} \mathrm{C}$, momento em que se adicionou cultura liofilizada contendo Streptococcus salivarius subsp. thermophilus e Lactobacillus delbrueckii subsp. bulgaricus (Chr-Hansen ${ }^{\circledR}$, Valinhos, São Paulo, Brasil). A mistura foi incubada a $45^{\circ} \mathrm{C}$, com monitoramento da acidez titulável até que fossem atingidos, aproximadamente, $80^{\circ}$ Dornic. Procedeu- 
se, então, à quebra do gel, por agitação manual, com simultânea adição da polpa e rápido resfriamento a $12^{\circ} \mathrm{C}$. As bateladas fabricadas foram mantidas sob resfriamento a $12^{\circ} \mathrm{C}$ por 24 horas para maturação, sendo, posteriormente distribuídas em embalagens de polietileno higienizadas e identificadas para as análises nos tempos pretendidos. Os iogurtes prontos foram estocados sob refrigeração $\left(4^{\circ} \mathrm{C}\right)$.

Quantificação de bactérias lácticas, análises físico-químicas e de textura foram realizadas no tempo inicial (24 horas após fabricação) e nos tempos 10, 20 e 30 dias após fabricação, para as quais foi utilizado o controle. Análises sensoriais e cromatográficas para descrição de voláteis foram conduzidas no tempo inicial de vida útil.

Testes de preferência, aceitação e intenção de consumo foram realizados com 80 provadores não treinados, verbalmente recrutados, utilizandose iogurte com tempo de 10 dias após fabricação (Registro Comitê da UFVJM No 087/12). Amostras de $50 \mathrm{~g}$ de formulações de iogurtes, em temperatura de, aproximadamente, $4^{\circ} \mathrm{C}$, foram apresentadas aos provadores em cabines, de forma aleatória, servidas em copos plásticos descartáveis, codificados com números três dígitos. Dados foram coletados através do preenchimento das fichas para informar preferência, aceitação (cor, sabor, aroma e consistência: escala hedônica de 9 pontos ancorados aos extremos 'desgostei muitíssimo' e 'gostei muitíssimo') e intenção de consumo (escala de 5 pontos ancorados nos extremos 'consumiria sempre' a 'nunca consumiria') (INSTITUTO ADOLFO LUTZ, 2008). Antes de se realizar a análise sensorial foram realizadas análises das condições higiênico-sanitárias, sendo enumerados coliformes $30^{\circ} \mathrm{C}$, coliformes $45^{\circ} \mathrm{C}$, bolores e leveduras (APHA, 2001).

Valores de $\mathrm{pH}$ foram determinados utilizando-se potenciômetro. A acidez ( ${ }^{\circ}$ Dornic) foi obtida pela titulação de alíquotas de 10 gramas das amostras, homogeneizadas em $10 \mathrm{~mL}$ de água destilada, com solução $\mathrm{NaOH}$ 0,1M (INSTITUTO ADOLFO
LUTZ, 2008). A massa seca (g.100g ${ }^{-1}$ ) foi obtida por diferença de umidade, a qual previamente obtida em estufa a $105^{\circ} \mathrm{C}$ (INSTITUTO ADOLFO LUTZ, 2008). Proteína (g. $100 \mathrm{~g}^{-1}$ ) foi determinada pelo método de semi-micro Kjeldahl, compreendendo as etapas de digestão, destilação e titulação com solução padrão de ácido clorídrico 0,1 mol.L $L^{-1}$ (INSTITUTO ADOLFO LUTZ, 2008).

Procedeu-se à quantificação de bactérias lácticas totais após o plaqueamento de alíquotas de interesse em profundidade, com adição de sobrecamada, utilizando-se ágar MRS (Himedia Laboratories, Mumbai, Índia). A incubação foi realizada em estufa BOD, com temperatura de $37^{\circ} \mathrm{C}$ por 48 horas. Os resultados foram expressos em log UFC.g ${ }^{-1}$ (APHA, 2001).

Para pesquisa de textura empregou-se texturômetro TA.XT plus Stable Micro Systems ${ }^{\circledR}$ acoplado com a probe A/BE com disco de compressão de acrílico de $35 \mathrm{~mm}$ de diâmetro. $\mathrm{O}$ equipamento foi calibrado com peso padrão de $5 \mathrm{Kg}$. Alíquotas das amostras foram homogeneizadas e inseridas no copo teste de acrílico até o preenchimento de $3 / 4$ de seu volume. A velocidade de compressão do teste foi de $1 \mathrm{~mm} / \mathrm{s}^{-1}$, pela distância de $30 \mathrm{~mm}$. Foram mensuradas firmeza (pico máximo positivo), consistência (área positiva do gráfico) e coesividade (pico máximo negativo), utilizando-se o programa Exponent Lite versão 5.1 (Stable Micro Systems ${ }^{\circledR}$ ).

A identificação de compostos voláteis foi obtida por cromatografia gasosa. Empregou-se cromatógrafo gasoso modelo QP2010 Shimadzu. Os resultados obtidos foram comparados com a biblioteca NIST para identificação dos compostos detectados. As condições experimentais incluíram:

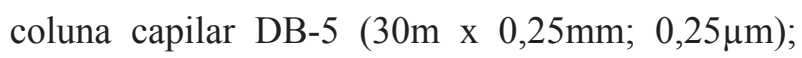
injeção em splitless; gás hélio para arraste; programação de temperatura da coluna de $40^{\circ} \mathrm{C}$ por $5 \mathrm{~min}$; aumento de $8^{\circ} \mathrm{C} / \mathrm{min}$ até $130^{\circ} \mathrm{C}$; aumento de $30^{\circ} \mathrm{C} / \mathrm{min}$ até $200^{\circ} \mathrm{C}$ e manutenção a $200^{\circ} \mathrm{C}$ por $5 \mathrm{~min}$; temperatura do injetor de $220^{\circ} \mathrm{C}$ e do detector de $250^{\circ} \mathrm{C}$. 
O experimento foi conduzido em delineamento inteiramente casualizado arranjado em esquema fatorial 4x4x3 (formulação, tempo e repetição). Os dados gerados pelas análises para quantificação de bactérias lácticas, análises físico-químicas e de textura foram submetidos a análises de variância e regressão, utilizando-se o programa estatístico Statsoft (STATSOFT, 2007).

A análise sensorial foi conduzida em blocos casualizados. Os dados gerados pelo teste de aceitação foram submetidos à análise de variância e teste de Tukey, em probabilidade de 5\%, utilizandose o programa estatístico Statsoft (STATSOFT, 2007).

Tabela 1. Preferência, escores médios de aceitação para cor, sabor, aroma e consistência e intenção de consumo para formulações de iogurte adicionadas com polpa de cajuí.

\begin{tabular}{ccccccccccc}
\hline $\begin{array}{c}\text { \%polpa } \\
\text { (m/g) }\end{array}$ & $\begin{array}{c}\text { Pref. }^{2} \\
(\%)\end{array}$ & \multicolumn{2}{c}{ Aceitação $^{3}$ (escore: $\left.0-10\right)$} & \multicolumn{9}{c}{ Intenção de consumo $\left.{ }^{8} \%\right)$} \\
\hline 5 & 31,43 & 7,0 & 6,7 & 6,4 & 6,9 & 20 & 27,14 & 38,57 & 10 & 4,29 \\
10 & 21,43 & 7,0 & 6,9 & 6,6 & 6,9 & 22,86 & 31,43 & 24,29 & 18,57 & 2,86 \\
15 & 24,29 & 7,0 & 6,7 & 6,4 & 7,0 & 17,14 & 34,29 & 32,86 & 11,43 & 4,29 \\
20 & 22,86 & 6,8 & 6,5 & 6,6 & 6,7 & 18,57 & 31,43 & 27,14 & 12,86 & 10 \\
\hline
\end{tabular}

${ }^{1}$ Percentagem de polpa adicionada $(\mathrm{m} / \mathrm{g})$; ${ }^{2}$ teste de preferência; ${ }^{3}$ teste de aceitação; ${ }^{4}$ cor; ${ }^{5}$ sabor; ${ }^{6}$ aroma; ${ }^{7}$ consistência; ${ }^{8}$ teste de intenção de consumo; ${ }^{9}$ comeria sempre; ${ }^{10}$ comeria frequentemente; ${ }^{11}$ comeria ocasionalmente; ${ }^{12}$ comeria raramente; ${ }^{13}$ nunca comeria. ${ }^{a}$ Médias seguidas por letras semelhantes não diferem entre si, de acordo com o teste de Tukey, em probabilidade de $5 \%$.

Fonte: Elaboração dos autores.

A contagem total de bactérias láticas, massa seca, firmeza, consistência e coesividade não se alteraram de forma significativa $(\mathrm{P}>0,05)$, seja em função da quantidade de polpa adicionada ou do período de armazenamento avaliado.

Para iogurtes formulados com cajuí não houve efeito significativo $(\mathrm{P}>0,05)$ das proporções de polpa adicionadas sobre a sua aceitação, no que se refere aos atributos cor, sabor, aroma e consistência, os quais foram ligeiramente ou moderadamente apreciados pelos avaliadores. Entretanto, a formulação com a menor quantidade de polpa adicionada (5\%) foi a mais preferida, a qual coincide com aquela na qual foi averiguada menor acidez. 
Tabela 2. Médias, coeficientes de variação (CV), coeficientes de determinação $\left(\mathrm{R}^{2}\right)$ e equações de regressão ajustadas para parâmetros químicos, contagem de bactérias láticas e textura em formulações de iogurte adicionado de diferentes concentrações de polpa de cajuí.

\begin{tabular}{|c|c|c|c|c|c|c|c|c|c|}
\hline \multirow[t]{2}{*}{ Parâmetros } & \multirow{2}{*}{$\begin{array}{l}\text { Tempo } \\
\text { (dias) }\end{array}$} & \multicolumn{5}{|c|}{ \% Polpa Cajuí (m/g) } & \multirow[b]{2}{*}{$\mathrm{CV}(\%)$} & \multirow[b]{2}{*}{$\mathrm{R}^{2}$} & \multirow[b]{2}{*}{ Equação } \\
\hline & & $\mathrm{C}$ & 5 & 10 & 15 & 20 & & & \\
\hline \multirow[t]{4}{*}{ acidez } & 0 & 0,82 & 1,04 & 1,16 & 1,24 & 1,23 & 1,76 & 0,91 & $\mathrm{Y}=129,23+(0,669 \mathrm{CJ})$ \\
\hline & 10 & 0,85 & 1,14 & 1,19 & 1,25 & 1,29 & & & $-(1,366 \mathrm{~T})-\left(0,01 \mathrm{CJ}^{2}\right)+$ \\
\hline & 20 & 0,88 & 1,21 & 1,22 & 1,27 & 1,34 & & & $\left(0,012 \mathrm{~T}^{2}\right)+(0,03153 \times \mathrm{CJ}$ \\
\hline & 30 & 0,92 & 1,34 & 1,34 & 1,36 & 1,39 & & & $\times \mathrm{T})$ \\
\hline \multirow[t]{4}{*}{$\mathrm{pH}$} & 0 & 4,5 & 4,43 & 4,18 & 3,85 & 3,75 & 0,84 & 0,90 & $\mathrm{Y}=4,357-(0,0466 \mathrm{CJ})+$ \\
\hline & 10 & 4,4 & 4,27 & 4,06 & 3,75 & 3,70 & & & $(0,019 T)+\left(0,0007 \mathrm{X}_{1}^{2}\right)-$ \\
\hline & 20 & 4,4 & 4,16 & 4,05 & 3,79 & 3,73 & & & $\left(0,0003 \mathrm{~T}^{2)}-(0,00069 \times\right.$ \\
\hline & 30 & 4,3 & 4,11 & 4,05 & 3,73 & 3,60 & & & $\mathrm{CJ} \times \mathrm{T})$ \\
\hline proteína & 0 & 2,98 & 2,64 & 2,58 & 2,36 & 2,26 & 10,1 & 0,86 & \\
\hline \multirow[t]{3}{*}{ g. $100 \mathrm{~g}^{-1}$} & 10 & 2,93 & 2,62 & 2,58 & 2,31 & 2,27 & & & $\mathrm{Y}=2,78238-(0,02809 \mathrm{CJ})+$ \\
\hline & 20 & 2,95 & 2,61 & 2,50 & 2,33 & 2,24 & & & $(0,0000364 \mathrm{~T})$ \\
\hline & 30 & 2,96 & 2,61 & 2,52 & 2,27 & 2,23 & & & \\
\hline massa seca & 0 & 19,5 & 19,4 & 19,7 & 19,1 & 18,8 & 4,82 & & \\
\hline \multirow[t]{3}{*}{ g. $100 \mathrm{~g}^{-1}$} & 10 & 19,4 & 16,5 & 17,7 & 15,6 & 17,0 & & & NS \\
\hline & 20 & 19,6 & 17,2 & 18,6 & 16,2 & 18,6 & & & \\
\hline & 30 & 19,6 & 17,2 & 19,2 & 16,4 & 18,0 & & & \\
\hline $\mathrm{CBL}$ & 0 & 9,91 & 8,95 & 9,69 & 9,18 & 10,4 & 1,03 & & \\
\hline $\log$ & 10 & 9,78 & 10,7 & 10,0 & 10,6 & 10,5 & & & NS \\
\hline \multirow[t]{2}{*}{ UFC. $\mathrm{g}^{-1}$} & 20 & 8,45 & 9,43 & 9,58 & 10,9 & 9,46 & & & \\
\hline & 30 & 8,4 & 8,90 & 8,58 & 7,87 & 8,82 & & & \\
\hline firmeza & 0 & 0,06 & 0,03 & 0,03 & 0,02 & 0,03 & 7,58 & & \\
\hline \multirow[t]{3}{*}{$\mathrm{g}$} & 10 & 0,05 & 0,02 & 0,04 & 0,02 & 0,02 & & & NS \\
\hline & 20 & 0,05 & 0,02 & 0,04 & 0,03 & 0,03 & & & \\
\hline & 30 & 0,05 & 0,03 & 0,05 & 0,03 & 0,03 & & & \\
\hline consistência & 0 & 1,38 & 0,76 & 0,76 & 0,63 & 0,64 & 16,9 & & \\
\hline \multirow[t]{3}{*}{ g.s } & 10 & 1,44 & 0,60 & 0,60 & 0,68 & 0,64 & & & NS \\
\hline & 20 & 1,65 & 0,68 & 0,68 & 0,64 & 0,71 & & & \\
\hline & 30 & 1,57 & 0,81 & 0,81 & 0,72 & 0,89 & & & \\
\hline coesividade & 0 & 0,11 & 0,04 & 0,04 & 0,02 & 0,04 & 11,9 & & \\
\hline \multirow[t]{3}{*}{ g } & 10 & 0,09 & 0,02 & 0,06 & 0,03 & 0,02 & & & NS \\
\hline & 20 & 0,08 & 0,03 & 0,07 & 0,04 & 0,02 & & & \\
\hline & 30 & 0,11 & 0,03 & 0,08 & 0,02 & 0,04 & & & \\
\hline
\end{tabular}

Legenda: CJ: percentual de polpa de cajuí; T: tempo; RMF: resíduo mineral fixo; CBL: contagem total de bactérias láticas; C: controle; NS: não significativo.

Fonte: Elaboração dos autores.

Maior proporção dos avaliadores demonstrou interesse no consumo frequente ou ocasional, sendo reduzida a proporção de avaliadores que nunca consumiriam este produto. Maior rejeição (nunca comeria) foi observada para a maior proporção de polpa adicionada (20\%). Para as demais formulações a rejeição (nunca consumiria) foi inferior a 5\%.
Conforme observado, quanto maior a quantidade de polpa adicionada significativamente menores $(\mathrm{P}<0,05)$ foram os valores para proteína no produto final. Tal fato se justifica por um efeito de diluição, pois a polpa de cajuí não representa boa fonte de proteína. Neste contexto, Silva et al. (2008) relata em sua pesquisa baixos teores deste constituinte 
para o cajuí $\left(1,18 \mathrm{~g} \cdot 100 \mathrm{~g}^{-1}\right)$. Além da adição da polpa, deve-se considerar a adição de açúcar $(10 \%$ $\mathrm{m} / \mathrm{g}$ ), a qual também promove redução no conteúdo de proteínas, por diluição. Havendo necessidade de se padronizar o teor protéico do produto final devese considerar o prévio enriquecimento de sólidos lácteos do leite, caso sejam utilizadas polpas como esta.

Os valores de acidez e $\mathrm{pH}$ de iogurtes foram significativamente afetados $(\mathrm{P}<0,05)$ tanto pela quantidade de polpa adicionada, quanto pela pósacidificação decorrente da atividade microbiana. Quanto maior a quantidade de polpa adicionada e quanto maior o tempo de estocagem, maior foi a acidez e menor o $\mathrm{pH}$ do produto.

Comparado ao iogurte controle, o caráter ácido da polpa de cajuí contribuiu para o aumento na acidez do produto, considerando-se que, ao fim da fermentação do leite os valores da acidez do gel estiveram ao entorno de $0,82 \mathrm{~g} \cdot 100 \mathrm{~g}^{-1}$ de ácido lático. Os valores de $\mathrm{pH}$ também foram reduzidos após a incorporação da polpa, considerando-se o pH inicial do gel monitorado e padronizado ao entorno de 4,5. Por esta razão, deve-se atentar à quantidade de polpa a ser adicionada para que não haja prejuízos à estabilidade do produto, à sobrevivência de bactérias lácticas, ao atendimento a padrões oficiais de identidade e qualidade e à aceitação pelo consumidor. Pontua-se novamente que nesta pesquisa os avaliadores preferiram formulações com menor concentração de polpa adicionada, o que coincide com menores valores de acidez e maiores valores de $\mathrm{pH}$.

Além da acidificação e redução do $\mathrm{pH}$ decorrentes da incorporação da polpa, deve-se considerar a persistência da atividade de bactérias láticas durante a estocagem do produto, fato descrito na literatura como pós-acidificação (VAHEDI; TEHRANI; SHAHIDI, 2008). Kauser et al. (2011) relata que, mesmo quando iogurtes são estocados sob condições de temperatura bacteriostáticas a microorganismos termófilos, ainda assim haverá alguma atividade microbiana fermentativa, suficiente para alterar a acidez do produto ao longo do tempo de armazenamento.

Um dos principais parâmetros de qualidade do iogurte consiste na sobrevivência e viabilidade de bactérias láticas (Lactobacillus delbrueckii subsp. bulgaricus e Streptococcus salivarius subsp. thermophilus), pelo menos durante o período de vida útil do produto. Por esta razão, ao se pesquisar novos aditivos e ingredientes deve-se avaliar a sua ação perante estes micro-organismos benéficos. Constatou-se, nas condições deste trabalho, que a polpa de cajuí não apresentou efeitos deletérios sobre a viabilidade destes micro-organismos, sendo que todas as formulações apresentaram-se dentro do padrão oficial para qualidade de iogurtes (BRASIL, 2007), o qual que estabelece valor mínimo de 7 Log UFC.g ${ }^{-1}$.

Embora não significativo, percebe-se tendência numérica na redução da densidade populacional de bactérias lácticas, em função do período de armazenamento. De acordo com Al-Kadamany et al. (2003) há normalidade em se observar tais reduções em iogurtes, as quais decorrem da própria atividade microbiana e da acidificação do meio.

Parâmetros de textura do iogurte são importantes tanto para a sua caracterização quanto para a sua aceitação pelo consumidor. Embora haja relato de que há tendência no aumento de sua firmeza, consistência e viscosidade em função do tempo de armazenamento (SECKIN; OZKILINC, 2011) não foi detectado efeito significativo $(\mathrm{P}>0,05)$, seja em função da quantidade de polpa adicionada ou do tempo de armazenamento, sobre os parâmetros firmeza, consistência, coesividade. Estes parâmetros de textura poderiam ser influenciados por modificações na capacidade de retenção de água, ocasionado por aumento da fração de sólidos e por seu perfil hidrofílico ou hidrofóbico. Conforme observado, não houve efeito significativo sobre a massa seca e, por esta razão, a textura observada no iogurte controle foi preservada mesmo após adição da polpa de cajui. 
Os compostos aromáticos identificados no iogurte com cajuí, extraídos por cromatografia gasosa (limite de quantificação $0,01 \mathrm{mg} \cdot \mathrm{Kg}^{-1}$ ) foram acetaldeído, acetona, diacetil, etanol, 2-aminoN-etilpropanamida, 1-hexanol, ácido hexanóico, hexanal, estireno, benzaldeído, butanoato de etila, 3-metil butanoato de metila, isovalerato de metila e butanoato de metila. Informa-se que a ocorrência de alguns destes constituintes pode ser sido proporcionada pela a adição da polpa, bem como produzidas no iogurte pela fermentação realizada por bactérias láticas.

A ocorrência de acetaldeído, acetona e diacetil em iogurtes é descrita na literatura (CRUZ et al., 2012). Estes compostos, produzidos pela atividade de L. bulgaricus e S. thermophilus, a partir de determinados constituintes do leite, têm sido descritos como os principais responsáveis pelo sabor e aroma característicos deste tipo de alimento (MACCIOLA; CANDELA; LEONARDIS, 2008). Nesta pesquisa estes compostos não foram quantificados, mas pesquisas sugerem quantidade de acetaldeído no iogurte com valores de 42 mg. $\mathrm{Kg}^{-1}$ (GUPTA; MITAL; GARG, 1997), diacetil 2,77 $\mu \mathrm{g} \cdot \mathrm{g}^{-1}$ (GUERRA-HERNÁNDEZ; ESTEPA; RIVAS, 1995), acetona $1,45 \mathrm{mg} \cdot \mathrm{kg}^{-1}$ e etanol 0, 35 mg. $\mathrm{kg}^{-1}$ (GEORGALA et al., 1995).

Além dos compostos aromáticos de ocorrência natural iogurtes podem veicular grande diversidade de outros compostos, os quais serão mais variados e a presença mais percebida tanto em função de ingrediente veiculado, assim como de sua quantidade adicionada. As polpas de frutas do cerrado apresentam grande diversidade de compostos voláteis, os quais são capazes de enriquecer o sabor e o aroma do iogurte, contribuindo para a inovação nesta categoria de lácteos.

Alguns dos compostos identificados nos iogurtes com cajuí são descritos por Assis et al. (2007) como responsáveis pelo aroma do suco de caju, outro pseudofruto do gênero Anacardium, os quais butanoato de etila e butanoato de metila, etanol, hexanal, benzaldeído e 3-metil butanoato de metila.

Considerar a produção de iogurtes empregando polpas de frutas de ocorrência no Cerrado é uma atitude bastante plausível para laticínios, principalmente aqueles instalados em regiões abrangidas por este bioma. O iogurte adicionado com cajuí foi, nas condições experimentais adotadas, bem aceito nos testes sensoriais e apresentou estabilidade durante o período de vida útil pesquisado, principalmente no que diz respeito à viabilidade de bactérias lácticas, parâmetro de qualidade fundamental a leites fermentados.

Conclui-se que o iogurte produzido com adição de polpa de cajuí em proporção de $5 \%$ foi bem avaliado em testes sensoriais e apresentou satisfatória estabilidade físico-química e reológica pelo período de 30 dias. A adição desta polpa contribuiu para a diversificação de compostos voláteis formadores de aroma e sabor no produto.

Fatores limitantes à qualidade e aceitação incluem elevação da acidez e redução do $\mathrm{pH}$, decorrentes da quantidade de polpa. Adição de maiores proporções de polpa acarreta em redução no teor de proteína do produto final.

\section{Agradecimentos}

Os autores agradecem a CAPES, FINEP e UFVJM pelo auxílio financeiro.

\section{Referências}

AL-KADAMANY, E.; KHATTAR, M.; HADDAD, T.; TOUFEILI, I. Estimation of shelf-life of concentrated yogurt by monitoring selected microbiological and physicochemical changes during storage. Lebensmittel Wissenschaft und Technologie, Zurich, v. 36, n. 4, p. 407-414, 2003. Available at: <http://dx.doi.org/10.1016/ S0023-6438(03)00018-5>. Accessed at: 12 ago. 2012.

AMERICAN PUBLIC HEALTH ASSOCIATION APHA. Compendium of methods for the microbiological examination of foods. 4. ed. Washington: APHA, 2001.

ASSIS, A. V. R.; BIZZO, H. R.; MATTA, V. M.; CABRAL, L. M. C. Recuperação e concentração 
de componentes do aroma de caju (Anacardium occidentale L.) por evaporação. Ciência e Tecnologia de Alimentos, Campinas, v. 27, n. 2, p. 349-354, 2007. Disponível em: <http://dx.doi.org/10.1590/S0101$20612007000200024>$. Acesso em: 06 maio 2012.

Ministério da Agricultura, Pecuária e Abastecimento. Instrução Normativa $n^{0} 51$, de 18 de setembro de 2002. Regulamentos técnicos de produção, identidade e qualidade do leite. Diário Oficial [da] União, Brasília, 20 set. 2002. Seção 1, p. 13. Disponível em: $<$ http://www.agricultura.gov.br $>$. Acesso em: 18 jan. 2012.

Ministério da Agricultura, Pecuária e Abastecimento. Instrução Normativa $\mathrm{N}^{\circ} 46$, de 23 de outubro de 2007. Regulamento técnico de identidade e qualidade de leites fermentados. Diário Oficial [da] União, Brasília, 24 out. 2007. Seção 1, p. 4. Disponível em: http://www.agricultura.gov.br>. Acesso em: 18 jan. 2012.

CRUZ, A. G.; CASTRO, W. F.; FARIA, J. A. F.; LOLLO, P. C. B.; AMAYA-FARFÁN, J.; FREITAS, M. Q.; RODRIGUES, D.; OLIVEIRA, C. A. F.; GODOY, H. T. Probiotic yogurts manufactured with increased glucose oxidase levels: postacidification, proteolytic patterns, survival of probiotic microorganisms, production of organic acid and aroma compounds. Journal of Dairy Science, Madison, v. 95, n. 5, p. 2261-2269, 2012. Available at: <http://dx.doi.org/10.3168/jds.2011-4582>. Accessed at: 03 mar. 2012.

GEORGALA, A. I. K.; TSAKALIDOU, E.; KANDARAKIS, I.; KALANTZOPOULOS, G. Flavour production in ewes' milk and in ewes' milk yoghurt by single strains and combinations of Streptococcus thermophilus and Lactobacillus delbrueckii subsp. bulgaricus, isolated from traditional Greek yoghurt. Le Lait - Dairy Science and Technology, Paris, v. 75, n. 3, p. 271-283, 1995. Available at: <http://dx.doi.org/10.1051/ lait:1995319>. Accessed at: 16 mar. 2012.

GUERRA-HERNÁNDEZ, E. J.; ESTEPA, R. G.; RIVAS, I. R. Analysis of diacetyl in yogurt by two new spectrophotometric and fluorimetric methods. Food Chemistry, London, v. 53, n. 3, p. 315-319, 1995. Available at: <http://dx.doi.org/10.1016/0308-8146(95)93939-O>. Accessed at: 05 maio 2012.
GUPTA, P. K.; MITAL, B. K.; GARG, S. K. Preparation and evaluation of acidophilus yogurt. Journal of Food Science and Technology, Mysore, v. 34, n. 2, p.168-170, 1997.

INSTITUTO ADOLFO LUTZ. Métodos físico-químicos para análise de alimentos. $4^{\mathrm{a}}$ ed. $1^{\mathrm{a}}$ ed. digital. São Paulo: IMESP, 2008. Disponível em: < http://www.ial.sp.gov. br>. Acesso em: 02 jan. 2012.

KAUSER, S.; SAEED, A.; KALIM, I.; SALARIYA, A. M.; IQBAL, M.Studies on the development and nutritional evaluation of apricot based yoghurt. Pakistan Journal of Biochemistry and Molecular Biology, Lahore, v. 44, n. 4, p. 156-159, 2011. Available at: <http:// www. $3 \mathrm{kbioxml}$.com/3k/index.php/PJBMB/article/ viewFile/321/195>. Accessed at: 04 abr. 2012.

MACCIOLA, V.; CANDELA, G.; LEONARDIS, A. Rapid gas-chromatographic method for the determination of diacetyl in milk, fermented milk and butter. Food Control, Vurrey, v. 199, n. 9, p. 873-878, 2008. Available at: <http://dx.doi.org/10.1016/j.foodcont.2007.08.014>. Accessed at: 08 abr. 2012.

SECKIN, A. K.; OZKILINE, A. Y. Effect of some prebiotics usage on quality properties of concentrated yoghurt. Journal of Animal and Veterinary Advances, Lahore, v. 10, n. 9, p. 1117-1123, 2011. Available at: $<$ http://dx.doi.org/10.3923/javaa.2011.1117.1123>. Accessed at: 18 mar. 2012.

SILVA, M. R.; LACERDA, D. B. C. L.; SANTOS, G. G.; MARTINS, D. M. O. Caracterização química de frutos nativos do cerrado. Ciência Rural, Santa Maria, v. 38, n. 6, p. 1790-1793, 2008. Disponível em: <http://dx.doi. org/10.1590/S0103-84782008000600051>. Acesso em: 20 mar. 2012.

STATSOFT. Statistics. Data analysis software system. Version 8.0, Tulsa: Statsoft, 2007.

VAHEDI, N.; TEHRANI, M. M.; SHAHIDI, F. Optimizing of fruit yoghurt formulation and evaluating its quality during Storage. American-Eurasian Journal of Agricultural \& Environmental Science, Dubai, v. 3, n. 6, p. 922-927, 2008. Available at: <http://www.idosi. org/aejaes/jaes3\%286\%29/20.pdf>. Accessed at: 08 jul. 2012. 